The earwig is said to be economically unimportant; but the hazard of staining skin and mistaking it for a malignant melanoma might be costly if future patients are evacuated from tropical countries.

I thank Dr M W Service, Liverpool School of Tropical Medicine; Mr A Brindle, Manchester Museum, Manchester University; and Dr B R Laurence, London School of Hygiene and Tropical Medicine for their help; and Mr C Forster for the photograph.

${ }^{1}$ Andrade, R, in Clinical Tropical Dermatology, ed O Canizares, p 397. Oxford, Blackwell, 1975.

(Accepted 10 April 1979)

Galmi Hospital, BP 44, Madaoua, Niger Republic, West Africa

ANDREW R POTTER, MB, BCHIR, medical officer (now senior house officer, Department of Anaesthetics, Royal Berkshire Hospital, Reading)

\section{Scrum-pox caused by herpes simplex virus}

Rugby football players know that skin infections may be transmitted by bodily contact. Forwards in particular are likely to develop facial lesions from face-to-face contact in scrums. Players refer to the skin lesions by various names including "scrum-pox," "prop-pox," and "impetigo." Some of these infections are undoubtedly bacterial and there have been cases of herpes simplex ${ }^{1-3}$ and vaccinia ${ }^{4}$ virus infection which were either acquired or exacerbated in rugby scrums. Herpes simplex virus infection in rugby players has been called herpes gladiatorum, herpes venatorum ${ }^{2}$ (Latin: venator, sportsman), and even herpes rugbeiorum. ${ }^{3}$ During 1978-9 seven of our St Mary's Hospital first fifteen developed facial lesions, five of them caused by herpes simplex virus. All were forwards. The lesions were difficult to diagnose, mainly because two of the first three patients had particularly severe and extensive eruptions. From conversations with players in other clubs we gained the impression that skin problems had been more common and widespread than in previous seasons. We therefore decided to conduct a small survey of rugby clubs in England to investigate the extent of these infections.

\section{Methods and results}

Swabs from our own players were placed in virus transport medium which was then inoculated into cultures of human embryo fibroblast cells (MRC5) and Vero cells. Swabs were also cultured for bacteria and fungi by standard methods. Herpes simplex viruses were typed by pock size on the chorioallantoic membrane of fertile hens' eggs. So far as we can determine from correspondence similar methods were used in other laboratories.

Clinical details of 48 cases of skin disease (scrum-pox) in rugby football players

\begin{tabular}{|c|c|c|c|c|c|}
\hline \multirow{2}{*}{$\begin{array}{c}\text { Clinical } \\
\text { diagnosis }\end{array}$} & \multirow{2}{*}{$\begin{array}{l}\text { Laboratory } \\
\text { confirmed }\end{array}$} & \multirow{2}{*}{$\begin{array}{l}\text { No of } \\
\text { cases }\end{array}$} & \multicolumn{3}{|c|}{ Treatment and No of cases } \\
\hline & & & Idoxuridine & Antibiotics & $\begin{array}{c}\text { None or } \\
\text { not known }\end{array}$ \\
\hline H simplex $\ldots$ & + & 13 & $7(4 \cdot 8)$ & $2(14)$ & \\
\hline $\begin{array}{l}\text { H simplex } \\
\text { Impetigo }\end{array}$ & $\bar{t}$ & $\begin{array}{l}8^{*} \\
1\end{array}$ & $8(5 \cdot 5)$ & $1(7)$ & \\
\hline Impetigo $\quad .$. & - & 16 & & $16(8 \cdot 5)$ & \\
\hline Impetigo zoster $\dagger$ & - & 1 & & 1 & \\
\hline Scrum-pox/prop-pos & - & 9 & & 5 & $4(14)$ \\
\hline
\end{tabular}

*Diagnosis based on two previously confirmed cases of identical appearance. †Diagnosis of impetigo revised to herpes zoster on failure to respond to antibiotics. Numbers in parentheses denote mean duration of rash in days (if known).

Seventy English rugby union clubs were selected to give a representative sample. Questionnaires were sent to their secretaries asking for details of any cases of skin disease. We specifically asked for the diagnosis, duration, and treatment of infections; the position in the field of the player; and details of possible contacts within the team and in their opponents.

Viruses isolated from the five cases in our team were confirmed as herpes simplex virus type 1 . Replies were received from 30 other clubs, 13 of them reporting recent skin disease in their players. A total of 48 players were affected, of whom 47 were forwards and one a scrum-half. Of the 47 forwards 32 played in the front row of the scrum, eight in the second row, and seven in the back row. Direct contact with opponents who had obvious skin lesions was reported by 23 , and 34 described similar contacts within their own team. Details of all the cases are shown in the table. Only one of the 18 cases diagnosed as impetigo was confirmed bacteriologically. Some of the 25 who had antibiotic treatment without laboratory support and were diagnosed as scrum-pox or impetigo may in fact have had herpes simplex virus infection.

\section{Comment}

There are $1850+10$ clubs registered with the Rugby Football Union in the United Kingdom. The results of this small survey of 70 English clubs suggest that there has been a nationwide problem of cross infection within rugby scrums. We have no evidence that 1978-9 was different from previous seasons although a number of players and club secretaries have expressed this opinion. We emphasise, however, that our results may be biased by the fact that the clubs reporting confirmed herpes simplex infection were associated with universities which have active virology laboratories. Only four of the clubs were attached to universities and there had been no fixtures between these teams before the time of the survey.

Some players concede that the "gentleman's agreement" which prevents them from playing if they have skin trouble tends to be forgotten before important fixtures. From the contact histories obtained in this survey this appears to occur often. Several of our own cases presented with extensive areas of vesiculation and one was admitted with pronounced systemic symptoms and shingles affecting the right third cervical nerve. Two others had received topical antibiotics for supposed impetigo before bacteriological tests were found to be negative and herpes simplex virus had been isolated. Once a firm diagnosis of herpes simplex virus infection had been established, patients were treated with topical idoxuridine $(5 \%$ in dimethyl sulphoxide). The index case in our local outbreak has had two extensive recurrences in the mandibular region within three months. Every attempt should be made to achieve a laboratory diagnosis in "scrum-pox" in order to initiate appropriate therapy as soon as possible and thus to prevent spread of infection in the patient and to others. The fact that the skin disease is confined almost exclusively to forwards and particularly those in the front row strongly suggests that infection is acquired on the field and not in the changing room or communal bath.

We thank the secretaries of the rugby union football clubs who assisted us and Bristol Public Health Laboratory for details of cases in previous years. We are grateful to the medical officers of the English and Irish rugby football unions for helpful discussion.

${ }^{1}$ Public Health Laboratory Service, Communicable Disease Reports No 15, 1974,1 .

2 Mare, J B, Keyzer, C M J, and Becker, W B, South African Medicalfournal, $1978,54,752$.

${ }^{3}$ Verbov, J, and Lowe, N J, Lancet, 1974, 2, 1723

4 Waddington, E, et al, Transactions of the St Fohn's Hospital Dermatological Society, 1964, 50, 22.

(Accepted 12 October 1979)

Departments of Virology and Bacteriology, St Mary's Hospital Medical School, London W2 1PG

P SHUTE, medical student

D J JEFFRIES, BSC, MRCPATH, senior lecturer in clinical virology

ANNE C MADDOCKS, BM, MRCPATH, senior lecturer in clinical bacteriology

$=\cdots$

\section{Before-and-after comparisons: a cautionary tale}

Most epidemiologists today agree that a "medical advance," be it a new drug or new technology, is best evaluated by a randomised controlled trial. This is usually accepted when it comes to drugs, but when we begin speaking of a new technology or a new surgical operation the waters become rather muddied. Then difficulties, both ethical and practical, become very obvious and when senior clinicians voice their impatience and doubts it is not surprising that others follow their lead. It seems so obvious that if results of treatment are known before the new method is introduced and are carefully monitored afterwards a simple comparison is all the evaluation required. The 
more sophisticated call for the "establishment of a data base." I report an example of the use of such before-and-after information.

\section{Patients, methods, and results}

At the Royal Melbourne Hospital in 1974 a prospective study was carried out on a consecutive series of 144 patients admitted over a six-month period with a clinical diagnosis of stroke (subarachnoid haemorrhage excluded). In 1978 this study was repeated with 182 consecutive patients admitted over the same period. In both series patients were followed from onset to death or to survival to three months. Between these two periods the only important change in the acute care of patients with stroke was the installation of a C-T head scanner.

This state of affairs seemed ideal for evaluating C-T scanning and its consequences in the care of stroke victims.

Paired analysis of effect on stroke survival of " $C-T$ scan" and "no $C-T$ scan"

\begin{tabular}{|c|c|c|c|}
\hline & & C-T scan & No C-T scan \\
\hline $\begin{array}{l}\text { Pairs with identical outcomes } \\
\text { Pairs where } 1978 \text { better than } 1974 \ldots \\
\text { Pairs where } 1978 \text { worse than } 1974 \ldots \\
\text { All pairs } \\
\text { Probability that differences in survival } \\
\text { and } 1974 \text { are due to chance }\end{array}$ & 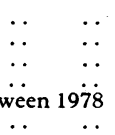 & 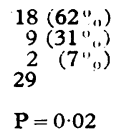 & $\begin{array}{l}38\left(43^{\circ}{ }^{\circ}\right) \\
34\left(38^{\circ}{ }^{\prime \prime \prime)}\right. \\
17\left(19^{\circ}{ }_{0}\right) \\
89 \\
P=0.006\end{array}$ \\
\hline
\end{tabular}

Successive patients in the 1978 series, who had been submitted to C-T scan, were matched with the next patient of the 1974 series of the same 5-year age group, diagnosis, and level of consciousness on admission. Twenty-nine such pairs were formed, the principle being that the 1974 pair-member would have had the scan had it been available. Using days survived from onset as the measured outcome a Willcoxon matched pairs, signed rank test was used to determine the likelihood of the difference in outcomes being due to chance alone. Eighteen of the 29 pairs had an identical outcome (survival to three months in all cases), in nine pairs the 1978 partner survived longer, and in two the 1974 patient (table). The difference was significan at the $2 \%$ level, and it appeared that the introduction of C-T scanning had much improved the chances of survival in patients admitted with stroke. Not being satisfied with this remarkable result, a second study was then carried out. By using the same matching technique, patients who in 1978 had not had C-T scan were paired with the next appropriate patient in the 1974 series. Eighty-nine such pairs were formed and the analysis (table) indicates that the apparent benefit of "not C-T scanned" to patients with stroke reaches even greater statistical significance.

\section{Comment}

The design of the study seems logical, the data were carefully collected, standard matching procedures were used, and the statistical analysis was appropriate. Nevertheless, the conclusions are quite misleading. The essential weakness of the before-and-after design is that over the period of study other changes are likely to have occurred in addition to the innovation being considered. In a randomised controlled trial, by way of contrast, both treatment and control groups are followed concurrently and thus "time bias" is eliminated. When pointing this out to students, and not infrequently to colleagues, the argument tends to be weakened by difficulty in giving a concrete example. A major change in case-fatality occurred between the series, and the explanation of the paradoxical results is simply that this change was independent of the introduction of the C-T scan. Beforeand-after studies are relatively easy, inexpensive, and, with the best will in the world, may be quite misleading in their results. The further apart the "before" and "after" periods the greater the risk, but the possibility needs careful consideration even in such shortterm studies as the popular cross-over designs used in many drug trials.

(Accepted 12 October 1979)

Department of Community Health, University of Melbourne, Victoria 3053, Australia

DAVID CHRISTIE, MD, FRACP, clinical epidemiologist
MEDICINE AS A CAREER Each of you has conceived a picture of his future as a student of medicine, in bright and sober colours according to his temperament, probably cheerful, simple, and perhaps with little meaning in it, but, as the future becomes the present, the visionary picture fades, and in its place is a real and totally different picture, beautiful or ugly as you shall paint it, but always of great significance and never without light and shadow.

Do not work only when the sun shines. Let no discouraging circumstance make you relax your efforts. Remember that some of the best work ever done has appeared for the time to be unfruitful, and that no one can always appreciate his progress. Real work never yet was a continuous pleasure; enthusiasm must ebb, and a sense of duty take its place.

Your energies must at first be devoted entirely to the acquisition and storing of facts; see that they be well arranged and tidily stored. The best student is not necessarily the man who learns most easily, but he who has made it his habit to keep in order the storehouse of his knowledge, that the grain of his harvesting be kept from decay. Of course memory is made up of psychical factors not possessed in an equal degree by everyone, but none the less it is true that effort and the habit of reflection are the essentials, without which the best natural gifts are worthless, and by means of which the least favoured may attain to high proficiency in the art of remembering. But you will not long remain mere collectors of facts; you will soon be able to use them with understanding in the process of thinking for yourselves-an exercise pleasurable even in the smallest matters. May I read to you some quaint words of John Locke?

"He that hawks at larks and sparrows has no less sport, though a much less considerable quarry, than he that flies at nobler game; and he is little acquainted with the understanding who does not know that as it is the most elevated faculty of the soul, so it is employed with a greater and more constant delight than any other. Its searches after truth are a sort of hawking and hunting, wherein the very pursuit makes a great part of the pleasure. Every step which the mind takes in its progress towards knowledge makes some discovery which is not only new but the best, too, for the time at least. For the understanding, like the eye, judging of objects only by its own sight, cannot but be pleased with what it discovers, having less regret for what has escaped it because it is unknown. Thus, he who has raised himself above the alms basket and, not content to live lazily on scraps of begged opinion, sets his own thoughts on work to find and follow truth will, whatever he lights on, not miss the hunter's satisfaction. Every moment of his pursuit will reward his pains with some delight, and he will have reason to think his time not ill spent even when he cannot much boast of any great acquisition." (From the British Medical fournal, 1900.)

SWALLOWING A DIAMOND We are indebted to SurgeonGeneral Bidie, CIE, (IMS retired) for sending us a local report of a curious case recently tried in Calcutta. A young man having provided himself with a new suit of clothes walked into a jeweller's shop and asked to look at a parcel of diamonds. He went to the window for better light, and presently it was discovered that the largest diamond, valued at Rs 10000 , had disappeared. An assistant noticed that the youth had carried his hand to his mouth suspiciously and the aid of the police was sought and the culprit sent to gaol, where he was placed under medical observation and "treatment." The gem did not appear, and it was suspected that it lay concealed in the man's throat. A skiagram was taken and revealed a foreign body in the throat which could not be dislodged. At the trial an old criminal swore that the concealment of stolen articles in the throat was a well-known habit of Indian thieves. It has been stated in Gould and Pyle's Anomalies and Curiosities of Medicine that some training and preparation are necessary for the success of this expedient. An artificial dilatation of the pharynx is produced by the means of a round leaden bullet, which is "swallowed" and brought up several times a day until a pouch is made which fulfils for stolen articles-coins and jewels-the same function as the crop in birds and rumen in ruminants. Concealment of stolen articles in the vagina and rectum and swallowing as a last resort are not unknown experiences in criminal practice in all countries, but the deliberate manufacture of a pharyngeal or oesophageal pouch for temporarily storing gems and coins is, as far as we know, peculiar to Hindustan. (From the British Medical fournal, 1900.) 